\title{
The ISN's Sister Renal Center program
}

\author{
Rashad Barsoum
}

It is now 10 years since Robert Schrier launched the International Society of Nephrology's (ISN's) Sister Renal Center program during the XIVth International Congress of Nephrology in Sydney, Australia. The idea of the program was to provide emerging centers in the developing world with focused support from established centers in the developed world, thus optimizing day-to-day practice. It was felt initially that all that was required was recognition and prioritization in the ISN's outreach programs. Limited financial support was provided to a few active 'model centers'. It soon became evident, however, that this approach had insufficient promotional reach; only a quarter of the partners that registered initially remained active 8 years after the program was launched.

So, in 2005, under the auspices of the Commission for the Global Advancement of Nephrology (COMGAN), the ISN restructured the Sister Renal Center program, significantly overhauling its mission, targets, administration and funding. The program is seen as a catalyst for building collaborations between two or more units, to the benefit of all partners. The 'Emerging Center' optimizes its services to become a regional reference center, engages in joint research with the 'Supporting Center', and becomes a leader in education, training and prevention. The Supporting Center attracts ISN privileges, is exposed to different diseases and populations, attains 'beyondthe-borders' experience, and gets a real-time sense of what the $85 \%$ global burden of kidney disease in the developing world means to our specialty. The ISN supports this collaboration for a limited period-usually 6 years-during which targets should be met, at least partially. It is hoped that such relationships will then continue autonomously, without the need for ISN support.

The framework for new Sister Renal Centers ('Level C') to train personnel and upgrade services is based upon joint support from the
The ISN

currently

supports 29

Sister Renal

Center pairs at

Level $\mathrm{C}$ and 10

pairs at Level B.

Each has

impressive

achievements

and plans...

$R$ Barsoum is Chair of the ISN's Sister Renal Center Committee.

\section{Competing interests}

The author declared he has no competing interests.

www.nature.com/clinicalpractice doi:10.1038/ncpneph0380
ISN and the respective Supporting Centers. After a defined minimum of educational support, the ISN matches any additional help provided by the Supporting Center. The ISN also provides free access to the Library Enhancement Program and informatics support, and grants priority in its Fellowship, Senior Scholarship, CME and Prevention programs, and travel grants.

When Level $\mathrm{C}$ center pairs reach a certain level of 'maturity', they can apply for an upgrade. This is a competitive process. Applications outlining previous achievements and definitive plans for the future are considered by an international committee, much in the way a research grant application is considered. The application must be concise, concrete and realistic. The committee scores the applications according to standard criteria, and the best are granted an upgrade to one of the premier Levels, B or A, with incremental logistic and financial support.

The expanding scope of the Sister Renal Center program demands strong administrative back up, which is provided by highly professional staff. Detailed policies-and-procedures documents are delivered to all stakeholders. Most procedures can be completed online, feeding a large database of all relevant details. To maintain personal contact with individual partners, each Sister Renal Center pair is linked to a member of the Sister Renal Center Committee, who provides advice, monitors progress and solves administrative problems.

The ISN currently supports 29 Sister Renal Center pairs at Level $\mathrm{C}$ and 10 pairs at Level $\mathrm{B}$. Each has impressive achievements and plans, which will be on show during the 2007 World Congress of Nephrology in Rio de Janeiro, Brazil. Our 2007 target is 50 Level $C$ pairs and 15 pairs at Levels $B$ or $A$. The annual budget for supporting this activity is over half a million US dollars. Every effort is being made to recruit more funds to accommodate increasing demand for what is one of the most promising initiatives of the ISN. 